\title{
OCBILs, YODFELs, and NENEGOLs
}

S tephen Hopper, director of the Royal Botanic Gardens, Kew, recently published an article describing special regions of the world that he terms OCBILS, or Old, Climatically Buffered Infertile Landscapes (Hopper 2009). Hopper argues that conservation and restoration of very old, weathered landscapes like those found in southwestern Australia, South Africa's Cape region, and Venezuela's Pantepui highlands require a rethinking of conventional ecological theory. These are places where an absence of recent glaciations or other major disturbances is an important factor in creating plant life that is extraordinarily diverse, long-lived, marked by a high number of rare endemics, and reflects a number of coping strategies for living on infertile soil, such as symbiosis, carnivory, parasitism, and salinity tolerance.

Hopper describes landscapes where most of us live as YODFELs-Young, Often-Disturbed Fertile Landscapes, and argues that ecological theory needs some opening up and new approaches in order to contend with OCBILs, because YODFELs have informed most of the thinking in the field.

Having recently visited Australia's southwestern floristic region, I require no convincing that novel approaches are needed in order to conserve and restore that unique landscape, which superficially reminded me so much of my desert home in the southwestern United States, but which struck me as impossibly strange and different once I got out of the bus and took a close look at the plants. Ecological restoration in places with rare, very long-lived plants with variable life cycles clearly presents a particular challenge.

Returning home from Australia to the YODFEL of the urban Midwestern United States, however, it seemed to me that here too, restoration was far from automatic or predictable. Although I can't measure up to Hopper's elegant distillation of the critical role of landscape age, climatic buffering, and soil fertility, I am motivated to think about the landscape-scale factors that might differentiate some YODFELS from others.

Much of the landscape of the University of WisconsinArboretum, where I work, for example, is not so much a YODFEL as it is a NENEGOL-a New, Negotiated Landscape. The factors that play a definitive role in how

Ecological Restoration Vol. 28, No. 1, 2010

ISSN 1522-4740 E-ISSN 1543-4079

(C2010 by the Board of Regents of the University of Wisconsin System. ecological restoration happens include new communities of species and changed ecological processes, but also the ongoing prevalence of human management-a kind of negotiation between humans but also between plant and animal species as well as between humans and other species.

In the NENEGOL of the UW-Arboretum, for example, we have several remarkable and renowned examples of restored prairies, especially Curtis and Greene prairies, which were restorations of old agricultural fields to native prairie plantings begun in the 1930s and 1940s. The prairies rely on year-round inputs of human labor to clear brushy vegetation, plant, and set fires in the spring or fall, or both. Throughout the year, volunteers prune, cut, herbicide, remove whole plants using weed wrenches and tug-a-suckles, girdle unwanted trees, remove seed heads, and generally work to pull significant amounts of biomass from the system. We look on other plants more fondly, and for those we collect seed, coax seedlings in our greenhouse, and transplant and nurture them toward maturity in the field. Fires occur on a much diminished scale and are highly controlled by humans. The hydrological cycle is also strongly influenced by people, and after big rains, the miles of impermeable surface surrounding the Arboretum result in strong pulses of water carrying high levels of sediments as well as heavy metals and other pollutants from lawns, roads, and parking lots.

To some extent, then, even our restored prairie landscapes are the "novel ecosystems" described by Richard Hobbs and colleagues as "new combinations of species that arise through human action, environmental change, and the impacts of the deliberate and inadvertent introduction of species" (Hobbs et al. 2006, 1). Novel ecosystems are not necessarily new (Lindenmayer et al. 2008), but the NENEGOL outside my office window has a fundamentally changed hydrology, and plant and animal species composition with no precedent. Although we aim for control of the landscape, radical changes in ecological regime and processes, such as hydrology, means that species' behavior and interactions can be entirely unpredictable.

These NENEGOLS are also shaped by social negotiation. One of the largest challenges of restoration in this place is how to resolve human conflicts and to manage ongoing issues that stem from values, economics, and public safety as much as from ecology. This is what the Arboretum faces with stormwater management planning, for example, in which we contend with the practices of 
thousands of urban neighbors and in the context of federal and state regulations with strict guidelines. When we burn prairies, we also pursue smoke management, taking into consideration visibility on the adjacent highway and the lungs of people in downwind residential areas. A routine semiannual exercise in maintaining ecological well-being is also perceived as risk taking with people's health, property, and safety.

In trying to comprehend the importance of ongoing human negotiation and management to the restored prairie landscapes at the UW-Arboretum, I was reminded of ecological and cultural restoration work I learned about at the recent Society for Ecological Restoration International conference in Perth, Australia. I heard presenters describe problems with "neglected landscapes," suffering because they were empty of the human management that is integral to ecological health. The health and productivity of land were described as dependent on regular human visits; places must be occupied, used, and talked about. Storytelling, camping, and foraging ensure the reproduction of material, ecological, and mythical landscapes. Spiritual affiliation to a landscape accords both rights and responsibilities, including custodial responsibilities for keeping the land healthy and its species abundant (Sithole et al. 2007). The message was that many wild places in Australia are better off if there are people visiting often, observing (seeing, smelling touching, feeling), working, harvesting, talking about, singing, telling stories, remembering.

Certainly, the urban wildland of the UW-Arboretum is a far cry from the Australian bush, and the annual grind of removing grey dogwood and buckthorn and training one-time volunteers might seem impossibly remote from the caretaking of a Traditional Owner watching out for the well-being of the marine turtle or the dugong. Nevertheless, this illustration of how landscapes rely on attentive human nurturing and negotiation was a reassuring and inspiring image of ecological restoration for me, providing an example of how ongoing human affiliation, attendance, and mindfulness of restored places is critical to long-term health of this NENEGOL, including the nonhuman species occupying it.

\section{Mrill Ingram \\ Editor}

\section{References}

Hobbs, R.J., S. Arico, J. Aronson, J.S. Baron, P. Bridgewater et al. 2006. Novel ecosystems: Theoretical and management aspects of the new ecological world order. Global Ecology and Biogeography 15:1-7.

Hopper, S.D. 2009. OCBIL theory: Towards an integrated understanding of the evolution, ecology and conservation of biodiversity on old, climatically buffered, infertile landscapes. Plant Soil 322:49-86.

Lindenmayer, D., J. Fischer, A. Felton, M. Crane, D. Michael et al. 2008. Novel ecosystems resulting from landscape transformation create dilemmas for modern conservation practice. Conservation Letters 1:129-135.

Sithole B., H. Hunter-Xenie, L. Williams, J. Saegenschnitter, D. Yibarbuk et al. 2007. Aboriginal Land and Sea Management in the Top End: A Community-Driven Evaluation. Darwin NT: CSIRO. 